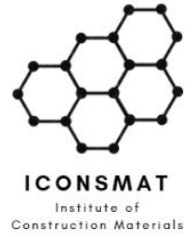

Content list available at ICONSMAT

Journal of Construction Materials

Journal homepage: www.iconsmat.com.au/publication

Article history:

Received 5 September 2020

Received in revised form

7 September 2020

Accepted 8 September 2020

Available online

2 October 2020

\title{
Mechanical contribution of silica fume and hydrated lime addition in mortars assessed by ultrasonic pulse velocity tests
}

\author{
Nacim Khelil ${ }^{1 *}$; Amar Kahil ${ }^{1 *}$; Said Boukais ${ }^{1 *}$ \\ 1* Corresponding authors: Civil Engineering Department, University of Mouloud Mammeri, Tizi-Ouzou, \\ Algeria; E: nacim.khelil@ummto.dz,amar.kahil@ummto.dz,said.boukais@ummto.dz
}

\begin{abstract}
The aim of the present study is to investigate the changes in the mechanical properties of mortars including additions of Condensed Silica Fume (CSF), Hydrated Lime (CH) or both at various amounts (5\% to $15 \%$ of cement replacement) and high water ratios $(\mathrm{w} / \mathrm{b})(0.4$ to 0.7$)$. The physical and mechanical changes in the mixes were evaluated using non-destructive tests (Ultrasonic Pulse Velocity (UPV)) and destructive tests (crushing tests) on 28 day-long specimens consecutively, in order to assess CSF and $\mathrm{CH}$ replacement rate influence on the mechanical and physical properties of the mortars, as well as CSF-CH pre-mixing on the improvement of these properties. A significant improvement of the mechanical properties of the CSF, CSF-CH mortars, has been noted. CSF-CH mixes showed the best improvements exceeding 50\% improvement, showing the sizable pozzolanic reaction contribution to the specimen strength development. UPV tests have shown increased velocities for CSF and CSH mixes, however no proportional evolution with compressive strengths could be noted. The results of the study show that CSF-CH addition could represent a suitable solution to significantly increase the mechanical properties of mortars.
\end{abstract}

DOI: 10.36756/JCM.v2.1.2 (C2020 Institute of Construction Materials

\section{Keywords}

Compressive strength; condensed silica fume; hydrated lime; pozzolanic reaction; UPV testing 


\section{Introduction}

by-products have widely been used to develop blended-cements, these supplementary cementitious materials, are used to enhance the mechanical and the physical properties of cements as they can play either a filler role (limestone filler $L$ ), or a pozzolanic role in the case of pozzolanas (silica fume SF, fly ash, Blast-furnace Slag) in which the pozzolana reacts the cement portlandite forming higher amounts of hydrates i.e. secondary C-S-H gels. The concrete additives, however, is not limited to the pozzolanic materials. Some of the recently developed environmental concrete additives are, for example, graphene oxide [1, 2] and a so-called concrete green solution [3, 4].

Tremendously used as a supplementary material, Silica fume which is a waste product of silicon and ferrosilicon alloys $[4,5]$ consists of $85-95 \%$ amorphous $\mathrm{SiO}_{2}$ in the form of fine spherical particles. Used in proportions from $5 \%$ to $15 \%$ of cement [6], it allows to achieve increased mechanical strengths [7].

Silica fume influences cement materials in many ways. The small particles of silica fume allow the cement hydrates to precipitate and grow on their surface, when homogeneously distributed throughout the matrix, the cement densifies in a uniform manner. Also, because of the pozzolanic property of silica fume, more hydration products are formed by the reaction between silica and portlandite, which contributes to fill the cement porosity, and therefore ameliorates permeability of cement [8].

To investigate the materials mechanical properties, the UPV test, which is a non-destructive technique, can be used [9]. Its results depend on many parameters, among which are mix proportions, aggregate nature and particle size, cement contents, etc. [10, 11]. UPV test relies on the measurement of an ultrasonic wave speed inside the material, consecutively to the placement of the specimen to be studied is placed between the apparatus emitting and receiving transducers. On denser material, faster ultrasonic waves are recorded indicating as a consequent, generally -on cement materials- higher mechanical properties.

\section{Materials and procedures}

\section{A. Materials}

The cement used in the study was a class $42.5 \mathrm{~N}$ Ordinary Portland Cement (OPC) from Lafarge and the CSF was a Granitex manufactured MEDAPLAST HP ${ }^{\circledR}$. $\mathrm{CH}$ used is a commercially available plain masonry $\mathrm{CH}$. The Chemical composition of the OPC and CSF are given in Table I. The sand aggregate (S) used is a siliceous sand from Asif N Sebaw Algeria, with maximum particle size of $4 \mathrm{~mm}$.

The mixing procedure used in the making process of the mortars was based on the BS EN-196-1 standard. The mixing consisted of a 4-minute process including slow and fast mixing speeds of different durations. After completion, mortar was immediately placed in $40 \mathrm{~mm} \times 40 \mathrm{~mm} \times 160 \mathrm{~mm}$ prismatic molds and vibrated, before sealing for $24 \mathrm{~h}$ at room temperature. Specimens were then demolded a water-cured until 28 days, before UPV testing and crushing.

The mortar mixtures tested are explained in section B. The testing process consisted of two consecutive steps. Firstly, a UPV test has been applied on the freshly retrieved specimens. The UPV measurement process has been performed using an instrument commonly referred to as the PUNDIT apparatus, which possesses two transducers, a generating transducer from which ultrasonic pulses are emitted, and a receiving transducer which receives the ultrasonic pulses and transforms it to an electrical signal. The results gathered after testing the specimens, are displayed on a monitor screen, and indicate the 
time taken by the ultrasonic wave to get through the specimen previously placed between transducers. Secondly, compressive tests through a hydraulic press has been performed.

Table 1 Chemical and physical properties of materials

\begin{tabular}{|c|c|c|}
\hline Chemical and physical properties & Cement & CSF \\
\hline $\mathrm{CaO}$ & 62.54 & 0.09 \\
\hline $\mathrm{SiO}_{2}$ & 21.80 & 93.8 \\
\hline $\mathrm{Al}_{2} \mathrm{O}_{3}$ & 5.35 & 0.12 \\
\hline $\mathrm{Fe}_{2} \mathrm{O}_{3}$ & 3.22 & 0.30 \\
\hline $\mathrm{SO}_{3}$ & 0.85 & 0.15 \\
\hline $\mathrm{MgO}$ & 1.18 & 0.9 \\
\hline $\mathrm{K}_{2} \mathrm{O}$ & 0.67 & 0.42 \\
\hline $\mathrm{Na}_{2} \mathrm{O}$ & 0.34 & 0.31 \\
\hline Loss of ignition & 3.63 & 3.42 \\
\hline Total & 99.58 & 99.51 \\
\hline
\end{tabular}

\section{B. Mix Design-Sample Preparation}

The experimental campaign consisted of casting cement mortar bars (40 mm x $40 \mathrm{~mm} \times 160 \mathrm{~mm}$ ) of sand-to-binder ratio $s: b=3: 1)$ and varying water-to-binder $w / b$ of $(0.4 ; 0.5 ; 0.6 ; 0.7)$. Cement substitution has been carried out at levels of $5 \%, 10 \%$ and $15 \%$. The substitution comprised either CSF, $\mathrm{CH}$, or a mix of both FS-CH in different proportions (0\%- 100\%, 25\%-75\%, 50\%-50\%, 75\%-25\%, 100\%$0 \%)$. Control specimens have also been cast during the procedure to assess the changes in properties induced by the substitution. All mortar specimens have consecutively to demolding, been immersed in water for a period of 28 days (water curing) prior to testing.

\section{C.UPV and Compressive Strength Testing}

Prior to the destructive mechanical tests, UPV tests have been performed in accordance with standard [12] using a pulse frequency of $150 \mathrm{~Hz}$. During testing process, the specimens underwent surface evening through the application of petroleum jelly (Vaseline) at the edges where the UPV apparatus is to be applied, the aim being to eliminate surface roughness negative effects on ultrasonic pulse transmission from the apparatus transducers to the specimens. The results displayed in the paper (ultrasound speed) expressed in $\mathrm{m} / \mathrm{s}$ are averaged values of three same-specimen takes. After performing UPV tests, the specimens were placed in a computer-monitored hydraulic press where they have been subjected to crushing tests, according to [13], at a constant rate of ((2400 \pm 200$) \mathrm{N} / \mathrm{s})$ in order to obtain the compressive strength. The records displayed in the paper are averaged values of three specimen test results.

\section{Compressive test results}

\section{A. Effect of Silica Fume}

The mortar specimens were prepared using cement pastes containing CSF from $0 \%$ to $15 \%$ at varying $\mathrm{w} / \mathrm{b}$ as mentioned. The 28-day strength test results are plotted against the $\mathrm{w} / \mathrm{b}$ ratios in Fig. 1. It can be 
seen that the 28-day compressive strength of the mortar mixes is markedly altered by the addition of CSF. At 0\% CSF (control specimen), no significant difference is observed when water amount increases ranging from $23.83 \mathrm{MPa}$ at $\mathrm{W} / \mathrm{b}=0.4$ (lowest) to $27.47 \mathrm{MPa}$ at $\mathrm{W} / \mathrm{B}=0.5$ (highest). At $5 \% \mathrm{CSF}$, a compressive strength optimum is observed, that for all specimens with $w / b=0.5$, while at $5 \%$ CSF and $w / b=0.6$ a pessimum is noted, for all the mixes having $w / b=0.6$. For mixes with $w / b=0.7$, a decrease in compressive strength is noted. A divergent behaviour is observed at $15 \%$ CSF, however. Indeed, the $w / b=0.6$ specimen shows a marked improvement in resistance beyond the pessimum, while the $w / b=0.7$ remains almost constant for all specimens and $w / b=0.5$ shows for its part a decrease of resistance. For $w / b=0.5$, the results can be explained by the amount of water being too small compared to the amount of CSF available for reaction. Indeed, the optimal value recorded could be explained by the amount of water and CSF being at equilibrium for reaction with each other, as silica fume increases while water amount being constant, high amounts of silica fume remain unreacted, For higher w/b ratios different behaviours have been observed; for $w / b=0.6$, more water is available to react with silica fume leading to the formation of more cementing material compared to the case discussed before, as CSF proportion increases a significant increase occurs in compressive strength, this means that more secondary C-S-H has been formed by the pozzolanic reactions occurring between silica fume and portlandite. For $w / b=0.7$, a stabilization phenomenon is recorded starting from $5 \%$ up to $15 \%$, this could be due to the high amount of water in the matrix which too significant, it transforms into porosity that decreases the compressive strength of the material or at least in that case stabilizes it, because of especially the formation of the secondary $\mathrm{C}-\mathrm{S}-\mathrm{H}$ which prevented the compressive strength from dropping abruptly.

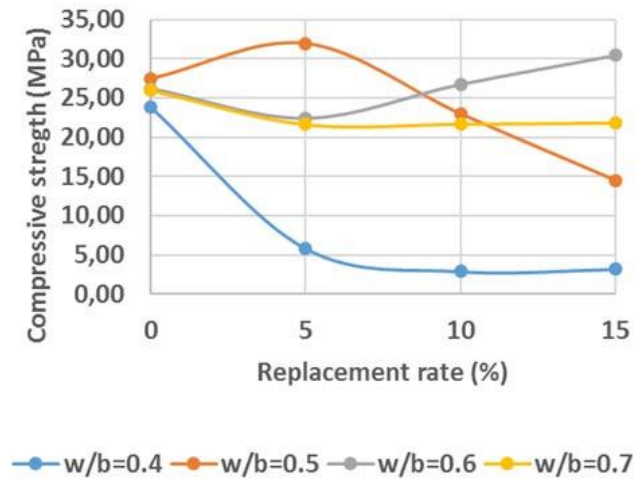

Figure 1 Compressive strengths of silica fume mixes at varying $\mathrm{w} / \mathrm{b}$ ratios and silica fume contents

\section{B. Effect of $\mathrm{CH}$}

The compressive strength development of the mortars containing $\mathrm{CH}$ at varying ratios are presented in Fig. 2. It can be observed that the addition of $\mathrm{CH}$ to cement leads to lower mechanical properties. Indeed, the higher the $\mathrm{CH}$ amounts present in the matrix, the higher the decrease in compressive strengths. $\mathrm{CH}$ is highly water consuming, its addition to the matrix therefore consumes large amounts of water, making it less available for reaction. At high w/b ratios (0.6 et 0.7$)$, the decrease of strength is less significant than that noticed on $\mathrm{w} / \mathrm{b}=0.4$. An explanation would be that for these mortars, more water is present in the mixes, even though a certain quantity is consumed by lime, sizable amounts remain in the matrix to react with cement. The decrease in compressive strength is due to two distinct phenomena; firstly, it is common knowledge $\mathrm{CH}$ is highly water-demanding [14, 15]; this has as a consequence, the consumption of a sizable amount of the water meant to react with the binder through the hydration process. Lesser water available for hydration, means lesser hydrated products formed, 
and therefore lesser compressive strength, since the amount of hydration products are positively correlated with the mechanical strength. On the other hand, $\mathrm{CH}$ does not have binding properties, any replacement by $\mathrm{CH}$, is equivalent to diluting the binding material i.e. cement with an inert material, that does not bring any mechanical improvement to cement matrix, hence, the lesser compressive strengths recorded.

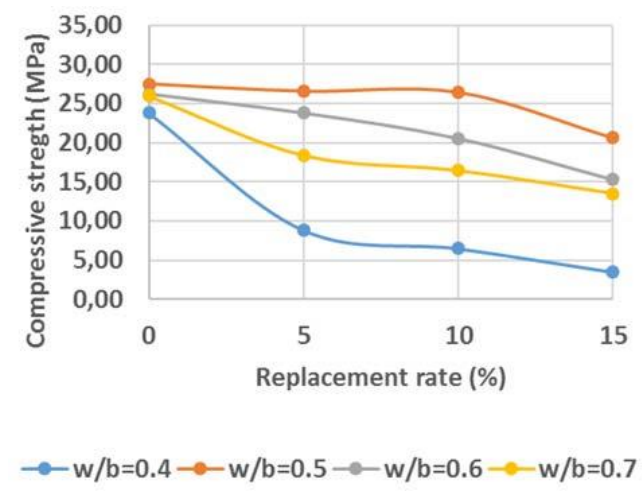

Figure 2 Compressive strength of $\mathrm{CH}$ mixes at varying $\mathrm{w} / \mathrm{b}$ ratios and hydraulic lime contents

\section{C.Effect of Silica Fume and $\mathrm{CH}$}

Fig. 3 shows two separate behaviours; the first one, is a resistance decrease exhibited by the 100CSF$\mathrm{OCH}$ mix, the decrease reaches $23 \mathrm{MPa}$ at $10 \%$ of cement replacement and $14.5 \mathrm{MPa}$ at $15 \%$ of OPC replacement. The second one, concerns the rest of the studied mixes, which all exhibit an improvement in mechanical resistance up to an OPC replacement proportion of $10 \%$ (optimum), afterwards, a decreasing phenomenon is noticed. As far as the silica fume replacement is concerned, the decrease in strength as the amount of silica increases, could be explained by the diluting effect of silica fume, indeed the addition of silica fume has been performed at the expense of cement which harbors fast hydraulic properties, whereas silica fumes pozzolanic properties are very slow, and depend on the portlandite production in the matric which is dependent on the amount of cement initially present in the matrix. Concerning the remaining mixes, especially the ones containing both silica fume and $\mathrm{CH}$, the increase of strength could be explained by the occurrence of pozzolanic reactions between both these two compounds, generating C-S-H gels which have mechanical properties.

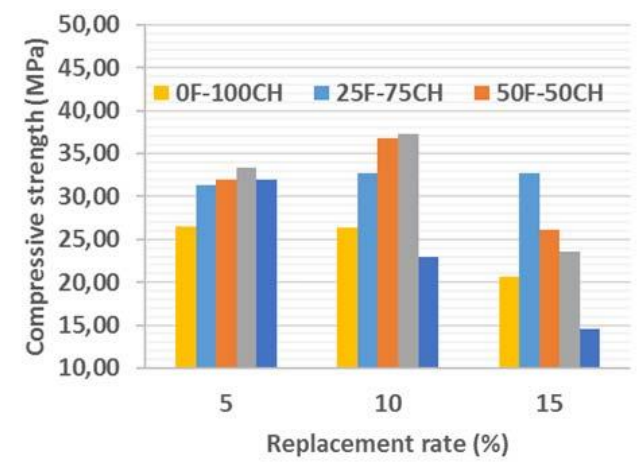

Figure 3 Compressive strength of silica fume $\mathrm{CH}$ at $\mathrm{w} / \mathrm{b}=0.5$ 


\section{UPV Test}

The results obtained after performing UPV tests on the mortar specimens are shown in Figs. 4-6. The results compared to compressive strengths, are evaluated and discussed below.

\section{A. The Effect of $\mathrm{CH}$ and Water on Compressive Strength-UPV Relationship}

From the results shown in Fig. 4, two influencing factors can be pinpointed, namely, the water-binder ratio and $\mathrm{CH}$ replacement rate. Indeed, it can be seen from the results obtained, that low $\mathrm{w} / \mathrm{b}=0.4$ mortars exhibit low velocity values due to both the water amount in the matrix being too low to react with cement particles and to $\mathrm{CH}$ water consumption preventing it from reacting with cement. The result is a high porosity matrix. $\mathrm{w} / \mathrm{b}=0.5$ represents the highest compressive strength and velocity values, increasing water content further shows a decrease in both these values. On these mixes, higher porosity is encountered. The ultrasonic pulse being transmitted faster in solids than liquids or void. a reduction of velocity is observed. Also, the compressive strength being tightly correlated with porosity, the highly porous media translates into a low compressive strength. of the specimens. $\mathrm{CH}$ also alters the compressive strengths. Mortars with $w / b=0.4$, the addition of lime improves velocity at the low replacement level of $5 \%$, when increased to $10 \%$ and $15 \%$, the inverse phenomenon is noticed which is due to a less dense material. For the other water contents, the addition of lime improves the velocities, meaning the matrix becomes denser with the addition of $\mathrm{CH}$, however, even though the matrix seems denser, no proportional improvement in terms compressive strength is noted, this is due to the fact that $\mathrm{CH}$ does not have hydraulic properties.

\section{B. The Effect of Silica Fume and Water on Compressive Strength-UPV Relationship}

From the results displayed in Fig. 5 , it can be noted that for low $w / b=0.4$ mortars, the lowest velocities are recorded. It is due to the small amount of water available in the matrix which leads to large amounts of unreacted cement particles. More water content in the matrix from $w / b=0.5$ to $w / b=0.6$ and 0.7 leads to a decrease of both strengths and ultrasonic velocities from $3915-4528 \mathrm{~m} / \mathrm{s}$ for $\mathrm{E} / \mathrm{C}=0.5$ to 3982 $4301 \mathrm{~m} / \mathrm{s}$ for $\mathrm{E} / \mathrm{C}=0.6$ to $3800-4156 \mathrm{~m} / \mathrm{s}$ for $E / C=0.7$. The results as explained previously, is due to the higher porosity of the cement matrix of the specimens consecutive to the increase of water content. The high void volume leads to lower UPV. The addition of silica fume however increases in some cases the velocities and compressive strengths recorded and decrease them in others. The seemingly random results obtained could be explained in the case of compressive strengths by the existence of optimums and pessimums for cement replacements which drives the amount of secondary C-S-H formed and which depends on the water content. Concerning the velocities, the results show that the addition of silica fume does not necessarily lead to a denser matrix, but can be detrimental.

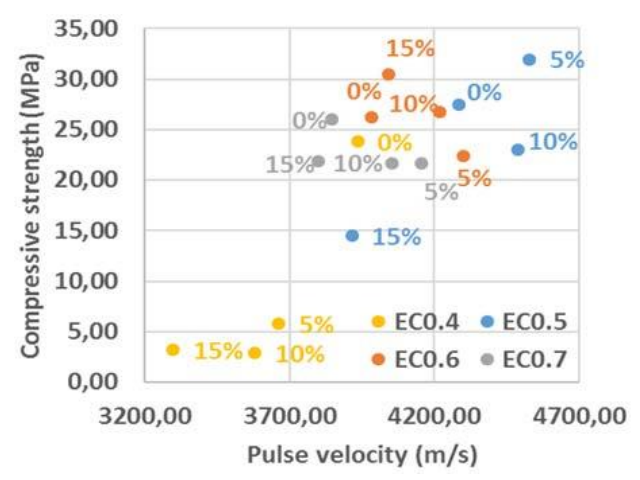

Figure 4 UPV vs Compressive strengths for $\mathrm{CH}$ mixes 


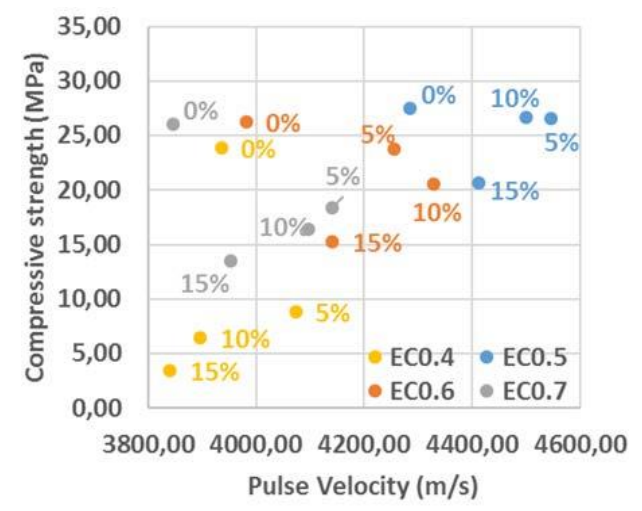

Figure 5 UPV vs compressive strengths for CSF mixes

\section{The Effect of Mixing CH-Silica Fume on Compressive Strength-UPV Relationship}

From Fig. 6 , it can be seen that the cement replacement has a marked impact on both pulse velocities and compressive strengths. Indeed, compared to the control $\operatorname{mix}(4285 \mathrm{~m} / \mathrm{s}, 24.47 \mathrm{MPa})$, a $5 \%$ replacement by FS-CH leads to an increase of pulse velocity to $4545-4707 \mathrm{~m} / \mathrm{s}$ while $10 \%$ replacement to $4417 \mathrm{~m} / \mathrm{s}-4860 \mathrm{~m} / \mathrm{s}$ and $15 \%$ replacement to $4301-4634 \mathrm{~m} / \mathrm{s}$. In terms of compressive strengths, almost all mixes exhibited improvements except mixes 15\%-CH75-FS25 and 15\% CH50-FS50. The highest compressive strength is recorded on mix 10\%-CH75-FS25 at $37.28 \mathrm{MPa}$, meaning this replacement ratio is the most efficient resistance-wise while it is the poorest in terms of pulse velocities. As far as the cement replacement rate is concerned, in general, the most efficient replacement rate, according to both compressive strengths and pulse velocities is the $10 \% \mathrm{mix}$; however, from what can be observed, higher pulse velocities do not necessarily mean higher compressive strengths. Indeed, as for $\mathrm{CH}$-only and FS only mixes, the higher velocities transcribe a denser matrix but not necessarily a high strength which is due to the formation of hydration products mainly C-S-H hydrates.

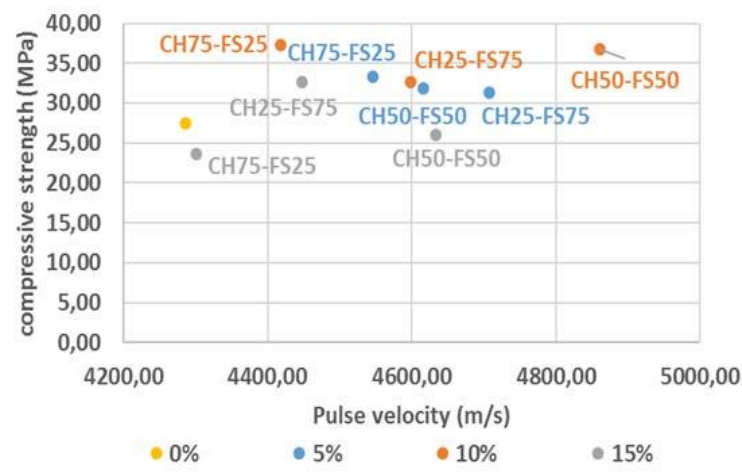

Figure 6 UPV vs compressive strengths for $\mathrm{CH}$-CSF mixes 


\section{Conclusion}

$\mathrm{CH}$ has an overall detrimental effect on the mechanical properties of mortars for all tested mixes while silica fume slightly improves the mechanical properties of the mortars tested. The addition of both $\mathrm{CH}$ and silica fume, however, positively influences the mechanical properties of mortars.

UPV test results are influenced by both W/B ratios and cement replacement rate. W/B= 0.5 exhibits the highest velocities and higher ratios lead to decreased velocities. For replacement rates, the higher replacement rates generally lead to higher velocities, however the highest replacement rate of $15 \%$ led to a decreased velocity.

$\mathrm{CH}$-CSF mixes showed the best strengths and velocities compared to CSF-only and $\mathrm{CH}$-only mixes due to the pozzolanic reaction occurring between the $\mathrm{CH}$ and the silica fume.

\section{References}

[1] F. Sartipi, A. Ghari Zadeh, and M. Gamil, "Electrical resistance of graphene reinforced cement paste," Journal of Construction Materials, 2019.

[2] M. Gamil, A. Ghari Zadeh, and F. Sartipi, "A review on graphene reinforced cement composite: technical approach for ecofriendly construction," Journal of Construction Materials, 2019.

[3] A. Gharizadeh, F. Sartipi, E. Ayoubi, and A. Severino, "The chemical reactor design configuration of CO2 concrete green solution," Journal of Construction Materials, vol. 1, pp. 2-5, 2020.

[4] A. Todhunter, M. Crowley, F. Sartipi, and K. Jegendran, "Use of the by-products of postcombustion carbon capture in concrete production: Australian case study," Journal of Construction Materials, vol. 1, no. 1, 2019, doi: https://doi.org/10.36756/JCM.v1.1.1.

[5] Ramezanianpour A. (2013). Cement Replacement Materials, Properties, Durability, Sustainability. Springer Geochemistry/Mineralogy: Heidelberg, Germany.

[6] Zhang M.H., Gjerv O. E. (1991), Effect of silica fume on pore structure and chloride diffusivity of low porosity cement paste, Cement and Concrete Research. Vol.21, 1006-1014.

[7] Mazloom M, Ramezanianpour A.A, J.J. Brooks (2004), Effect of silica fume on mechanical properties of high-strength concrete, Cement \& Concrete Composites Vol.26, 347-357.

[8] Dembovska L., Bajare D., Pundiene I, Vitola L., (2017). Effect of Pozzolanic Additives on the Strength Development of High Performance Concrete, Procedia Engineering Vol. 172, 202-210.

[9] Ohtsu M., Shigeishi M., Sakata Y. (1998). Nondestructive evaluation of defects in concrete by quantitative acoustic emission and ultrasonics.Ultrasonics Vol. 36, 187-195.

[10] Mohammed T.U., Rahman M.D. (2016). Effect of types of aggregate and sand-to-aggregate volume ratio on UPV in concrete. Construction and Building Materials Vol. 125, 832-841. 
[11] Lafhaj Z., Goueygou M., Djerbi A., Mariusz Kaczmarek (2006). Correlation between porosity, permeability and ultrasonic parameters of mortar with variable water/ cement ratio and water content. Cement and Concrete Research Vol. 36, 625 - 633.

[12] ASTM C597-2 (2002), Standard Test Method for Pulse Velocity Through Concrete, American Society for Testing Materials, Philadelphia, ASTM C597-2.

[13] BSI 196-1 (1995), Methods of testing cement-Part 1: Determination of strength, British standard institute.

[14] Prasanna Kumar Acharya, Sanjaya Kumar Patro, Narayana C. Moharana (2016), Effect of Lime on Mechanical and Durability Properties of Blended. Cement Based Concrete Vol. 97, 71-79.

[15] C. Ince, M. A. Carter, M. A. Wilson, N. C. Collier, A. El-Turki, R. J. Ball, G. C. Allen (2011). Factors affecting the water retaining characteristics of lime and cement mortars in the freshly-mixed state. Materials and Structures Vol.44, 509-516. 